\title{
Micro-morphologies of SBS modifier at mortar transition zone in asphalt mixture with thin sections and fluorescence analysis
}

Yue Xiao* (1), Mujaheed Yunusa, Boxiang Yan, Xiaoshan Zhang and Xiwen Chang

\begin{abstract}
The microstructure control of modified asphalt, especially the micro-dispersion of the SBS modifier in the mortar transition zone, is a critical technology for the performance design of modified asphalt. To characterize the microdispersive morphology of SBS modifiers, thin-section preparation techniques that can be used to analyze the original microstructure of the asphalt mixture were proposed and introduced in this study. Flexible resin is filled into the mixture at vacuum conditions to ensure accepted sample conditions for preparing thin sections of asphalt mixture. The morphology parameters, including SBS area ratio, box dimension, SBS average particle area and its coefficient of variation, area-weighted average axis ratio, and coefficient of variation, were plotted from fluorescence images to characterize the micro-morphological distribution of the SBS modifier in detail. Results have shown that the area ratio increased with the increase in SBS content, while the box dimension was reduced and the distribution uniformity of the particles decreased. The superfluous SBS modifier in the binder at a too high adding ratio will decrease the value of the box dimension. Lower modification temperature worsened the SBS modifier in the mixture, resulting in a wide range of particle size, higher axis ratio, and higher area ratio. The micro-morphologies of SBS in the asphalt mixture phase varied a lot from the asphalt binder phase. The additional materials of mineral filler and fine aggregate, together with the other heating processes, will significantly influence the swelling state and particle size of the SBS modifier.
\end{abstract}

Keywords: Asphalt mixture, Asphalt modifier, SBS modified asphalt, Fluorescence microscopic image, Thin section

\section{Introduction}

Asphalt pavement is laid and compacted from an asphalt mixture, considered a composite material with coarse aggregates, fine aggregates, mineral filler, asphalt binder, and other additives. The performance of the asphalt binder plays a vital contribution to the final road performance of asphalt pavement, although it is only weighted at around $5 \%$ of the whole mixture. Many innovative modifiers, including fibers $[1,23]$, polymers [26, 31], and Nano-clay [20], were developed to enhance the performance of asphalt binder. Among these modifications, SBS (Styrene-butadiene-styrene) modified asphalt binder is

\footnotetext{
*Correspondence: xiaoy@whut.edu.cn

State Key Laboratory of Silicate Materials for Architectures, Wuhan

University of Technology, Wuhan 430070, China
}

the most widely accepted material for prolonging the service life of asphalt pavement.

The microstructure of modified asphalt binder and the inner structures of a mixture are believed to influence the binder's performance and its corresponding mixture significantly. Many research methods have been developed for micro-scale inner structure analysis of asphalt mixtures. Wang et al. [24] used digital image processing techniques to quantify aggregate skeleton structure, including orientation, distribution, and contact properties of the aggregate. In collaboration with other laboratories, Hassan et al. [10] used X-ray computed tomography and optical microscopy to observe the internal structure of the mixture, especially the distribution of internal voids in recycled asphalt mixture. Navaro et al. [18] proposed a microscopic observation technique for observing the 
interface between new binder and aged binder in recycled asphalt pavement, then quantified the influence of production parameters, material temperature, and mixing time on the surface morphology of binder clusters. Xiao et al. [25] studied the SBS morphologies in asphalt binder with fluorescence technology and concluded the relationship between SBS morphologies and viscoelastic binder properties.

The modifier morphologies in asphalt mixtures are also widely studied but were seldom quantitatively characterized. The asphalt binder is widely accepted as a colloidal structure $[8,19]$, with a colloidal index describing the structure stability $[13,16]$. Such structuring in asphalt binder is a big challenge for asphalt modification. Sufficient distribution of modifiers and interfacial bonding are the critical issues for ensuring a high-performance modified binder. The Atomic force microscope, which can map different materials in the tested area, was used many years ago to study asphalt microstructures $[9,14]$. Shan et al. [22] used small-angle neutron to characterize the structure of the neat binder, SBS modifier, and SBS modified binder at the nanoscale and confirmed that the mechanism of SBS modification was a physical modification of the nanoscale structure.

However, only limited literature focused on the micromorphologies of SBS modifiers in the mortar transition zone of asphalt mixtures. The relationship between SBS morphologies in the asphalt binder situation and the situation in the asphalt mixture is still unknown. Moreover, research on the internal morphology structure of the SBS modifier in the asphalt mixture is of great significance for improving the service performance of the final asphalt pavement. Fluorescence microscopy technology, an image-based analysis technique, has played a vital role in polymer-modified asphalt research.

Therefore, the objectives of this research are:

1. Propose and prove a feasible specimen preparation method for fluorescence microscopy analysis. The specimen should be qualified for fluorescence image analysis to characterize the micro-dispersive morphology of SBS modifiers.
2. Define the image processing and analysis techniques to characterize SBS micro-dispersive morphologies in mortar transition zone in asphalt mixtures.

3. Characterize the SBS modifier in the mortar transition zone in an asphalt mixture, with cross-section specimens to provide an excellent technique to enhance the quality of the SBS modified binder and its corresponding mixture through improving the SBS morphologies in the mixture.

\section{Materials and research program Materials}

As Table 1 shows, an asphalt binder with a 69 penetration value and a $46^{\circ} \mathrm{C}$ softening point was used in this research for modified binder and asphalt mixture design. The Linear chemical structure SBS modifier, with physical properties displayed in Table 2, was used to modify the asphalt binder. Basalt was used under the mixture gradation design guide for asphalt mixtures. The finalized aggregate gradation of $\mathrm{AC}-13$ was presented in Table 3, with an optimal binder content of $4.9 \mathrm{wt} \%$.

The SBS modifier was added into the liquid asphalt binder gradually with a high-speed shear mixer, with the following modification process: First, the asphalt binder was heated to $145^{\circ} \mathrm{C}$ to ensure an acceptable low viscosity for adding the modifier. Secondly, a certain amount of SBS modifier was added into the liquid state of the asphalt binder, which was kept in a heated environment to ensure stable temperature conditions. Thirdly, the SBS

Table 2 Physichemical properties of the SBS modifier used for asphalt modification

\begin{tabular}{ll}
\hline SBS types & YH-792 \\
S/B ratio & $20 / 80$ \\
Volatile content & $\leq 0.7 \%$ \\
Ash content & $\leq 0.2 \%$ \\
Tensile strength & $24 \mathrm{MPa}$ \\
Elongation ratio & $\geq 730 \%$ \\
Failure strain & $\leq 55 \%$ \\
Configuration & Linear \\
Number average molecular weight & $1.0 \times 10^{5}$
\end{tabular}

Table 1 Physical properties of the used grade asphalt binder

\begin{tabular}{llll}
\hline Physical properties & Test results & Requirements & Specifications \\
\hline Penetration $\left(25^{\circ} \mathrm{C}, 100 \mathrm{~g}, 5 \mathrm{~s}\right), 01 \mathrm{~mm}$ & 69 & $60 \sim 80$ & T0604-2011 \\
Softenning point, ${ }^{\circ} \mathrm{C}$ & 46 & $\geq 44$ & $\mathrm{~T} 0606-2011$ \\
Ductility $\left(5 \mathrm{~cm} / \mathrm{min}, 15^{\circ} \mathrm{C}\right), \mathrm{cm}$ & $>100$ & $\geq 40$ & $\mathrm{~T}$ \\
Viscosity $\left(135^{\circ} \mathrm{C}\right)$, Pa.s & 284.5 & - & $\mathrm{T} 065-2011$ \\
\hline
\end{tabular}


Table 3 Aggregate gradation that used in this research

\begin{tabular}{llllllllll}
\hline Size $(\mathrm{mm})$ & 16 & 13.2 & 9.5 & 4.75 & 2.36 & 1.18 & 0.6 & 0.3 & 0.15 \\
Percent passing by weight (\%) & 100.0 & 94.3 & 80.4 & 50.4 & 28.4 & 21.0 & 15.0 & 11.3 & 8.075 \\
\hline
\end{tabular}

modifier was mixed with the liquid binder with a highspeed shear machine at a specific shear rate for $1 \mathrm{~h}$ to obtain a homogeneous modifier distribution. In the end, the SBS modified binder was placed in an oven at $100^{\circ} \mathrm{C}$ for at least $30 \mathrm{~min}$ to promote the swelling of the SBS modifier [7, 21]. Then, these modified asphalt binders were used for asphalt mixture design.

The literature claims that the modification process, including SBS adding content, conditioning temperature, high-speed shearing duration, and shearing rate, has a significant impact on the final properties of SBS binder due to the different distribution status of SBS modifier in asphalt binder resulting from different modification conditions $[2,30]$. Therefore, the influence of SBS adding content, modification temperature, and shearing rate on the SBS morphologies was studied. Investigated conditions include the modification conditions of $2 \mathrm{wt} \%$, $3 \mathrm{wt} \%, 4 \mathrm{wt} \%, 5 \mathrm{wt} \%$, and $7 \mathrm{wt} \%$ for SBS adding content, $130^{\circ} \mathrm{C}, 145^{\circ} \mathrm{C}, 160^{\circ} \mathrm{C}$, and $175^{\circ} \mathrm{C}$ for shearing conditioning temperature, and $2000 \mathrm{rpm}, 3500 \mathrm{rpm}$, and $5000 \mathrm{rpm}$ for shearing rate.

\section{Research program}

Figure 1 describes the research program using fluorescence microscope analysis to characterize the morphologies of SBS particles in the asphalt mixture with the help of the thin section preparation method. The SBS modifier was first added to the original asphalt binder under the modification conditions discussed in the previous section, and then the $\mathrm{AC}-13$ asphalt mixture was mixed and compacted. The thin section preparation method, which will be detailed explained in the section of the Micromorphology characterization method, was adapted to obtain the cross-section of asphalt mixtures. In the end, thin sections of the SBS modified mixture were placed under a fluorescence microscope to characterize the SBS morphologies quantitatively.

\section{Micromorphology characterization method}

Thin section preparation

Microscope analysis of material surface inspection always requires a flat surface with very low roughness to ensure precise imaging results $[6,27]$. Asphalt mixture, a porous

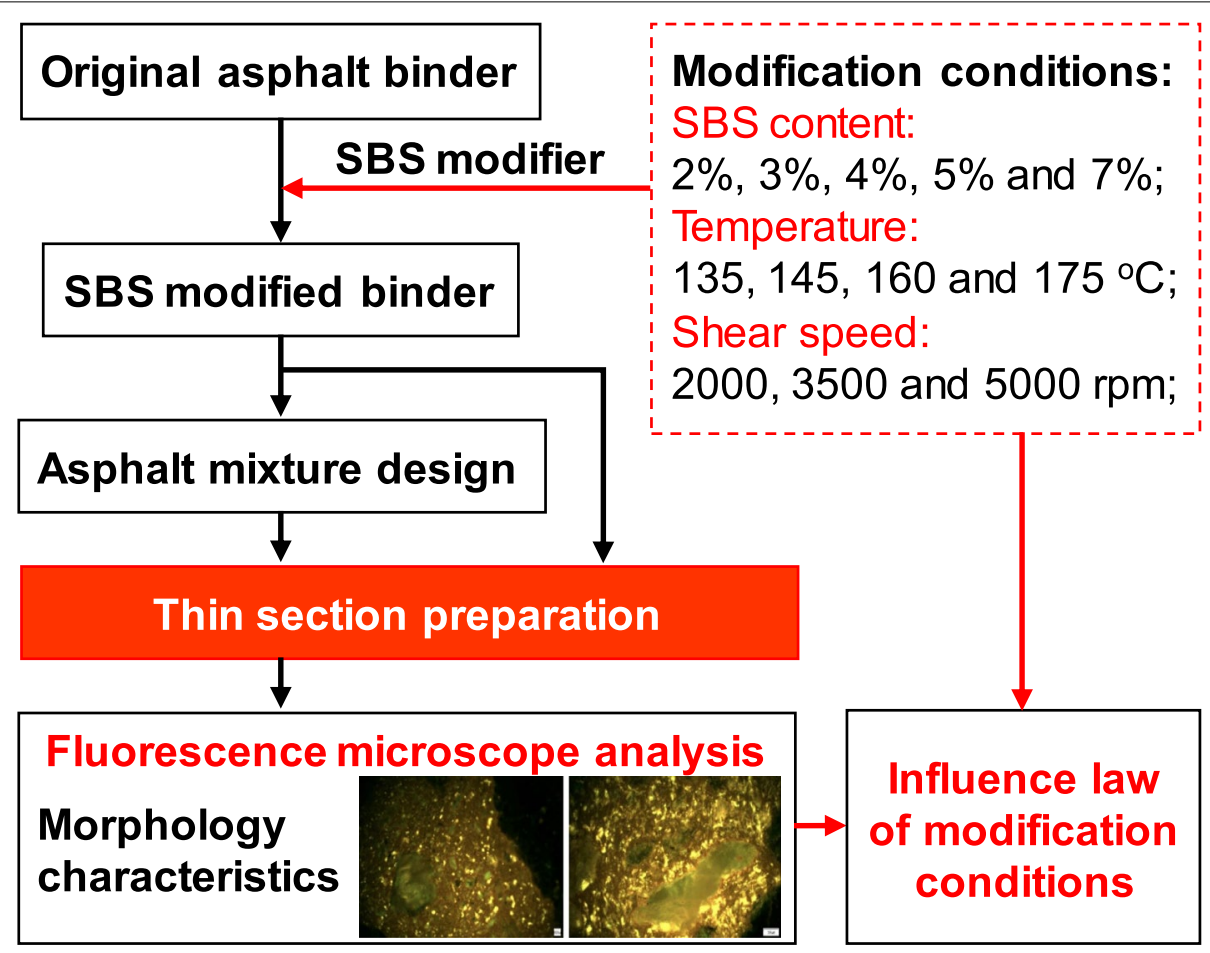

Fig. 1 Research program for SBS morphology characterization in asphalt mixture 
solid material containing hard and soft constituents, can not be directly used for microscope surface analysis [5, $12,18]$. The rough surface of the asphalt mixture will significantly decrease the imaging efficiency. Therefore, the thin section preparation method was proposed and approved to obtain a flat surface of asphalt mixture that enables precise imaging analysis. The experimental flow of thin section preparation is shown in Fig. 2, with steps of epoxy filling, cutting, and grounding. The detailed steps can be described as follows:

1. Specimens of asphalt mixture were cut into blocks of $2 \mathrm{~cm} \times 2 \mathrm{~cm} \times 5 \mathrm{~cm}$ or drilled into cylinders with a diameter of $3 \mathrm{~cm}$.

2. Epoxy was then filled into the air voids in the mixture by placing the specimen in liquid epoxy under vacuum for $5 \mathrm{~min}$ and then placed at room temperature for another $10 \mathrm{~h}$ for epoxy hardening to avoid microcracks during the second cutting stage for the thin specimen. The vacuum condition in which the specimen was placed was used in this research to ensure all trapped air was removed and replaced with liquid epoxy before hardening.

3. Epoxy-filled mixtures were then cut into thin specimens with a thickness of approximately $3 \mathrm{~mm}$. A specialized cutting machine (Fig. 2) was used in this step, a Struers Minitom cutting machine with an accuracy of $0.01 \mathrm{~mm}$.

4. The planned observation surface was grounded and then cleaned with a polishing machine and an ultrasonic washing machine. Ultrasonic washing of thin sections can then be used for fluorescence microscopic analysis.

With this thin section preparation method, a flat crosssection of asphalt mixture that retains its original inner micro-structure can be obtained for further microscope image analysis. Because alteration was not made even during the polishing stage, heat or reagents that could affect the morphology were not used. So the fluorescence microscopy study was carried out on the original asphalt mixture. Figure 2 shows an example of a fluorescence image of SBS-contained mortar in an asphalt mixture.

\section{Micromorphology characterization}

After the thin section of asphalt mixture was prepared, a fluorescence microscope was used to quantitatively analyze the dispersion form of the SBS modifier in the mortar transition zone between aggregates in the asphalt mixture. MATLAB (Matrix Laboratory) performed RGB (Red Green Blue) image analysis and processing with microscopic fluorescence images of the asphalt mixture. RGB means RGB color system. It constructs all the colors from the combination of the Red, Green, and Blue colors. The Red, Green, and Blue use 8 bits each, with integer values from 0 to $255[15,17]$.

Figure 3 presents the SBS morphology characterization steps. The distribution of the SBS modifier in the mortar area of the asphalt mixture is shown in Fig. 3a. This area contains a minimal amount of coarse aggregate (dark black-green part), mineral powder, fine aggregate, asphalt, and SBS modifier (bright green-yellow area). The fine mortar with a binder, mineral powder, and fine aggregate shows a light brown color. Firstly, to reduce the influence of the background caused by uneven light, the MATLAB imopen function was used to get the background of the analyzed image, and then the MATLAB imsubtract function was used to remove this background, which is presented in Fig. 3c. Secondly, RGB color image analysis and processing were conducted to define the pixel threshold of the SBS phase, mineral powder, and fine aggregate. As Fig. $3 \mathrm{~d}$ indicates, the black and white map of SBS distribution at the mortar transition zone in the asphalt mixture is obtained by self-programming,

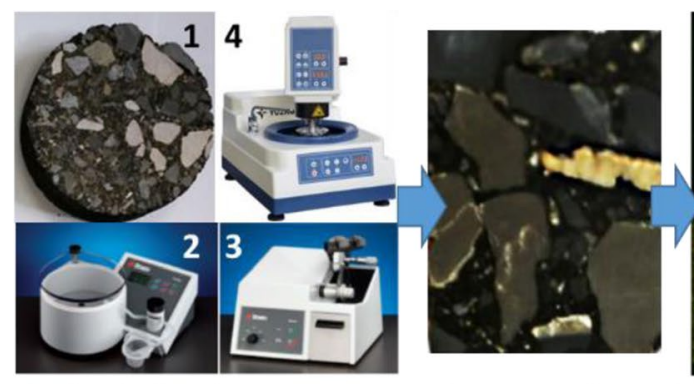

1. Asphalt mixture;

2. Epoxy filling;

3. Cutting; 4. Polishing;
- Cross section of asphalt mixture with flat surface

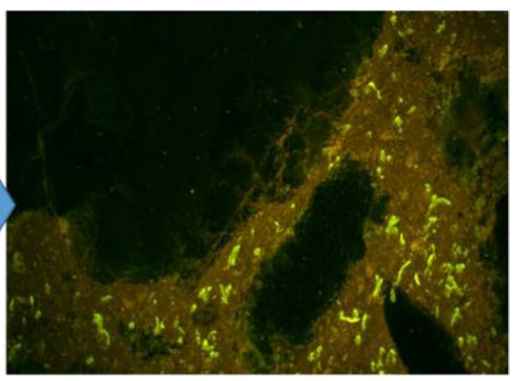

- Fluorescence image of mortar in asphalt mixture

Fig. 2 Thin section preparation of asphalt mixture for fluorescence microscopic analysis 

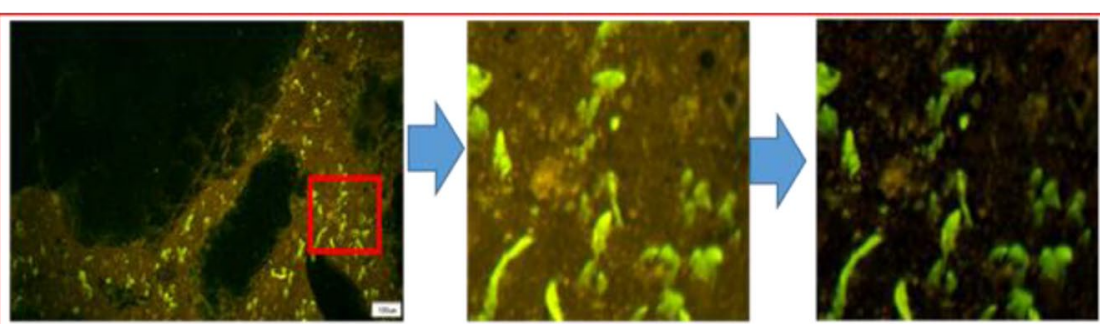

a: SBS in the mortar area

b: Selected analyzing area

c: Background filtered image

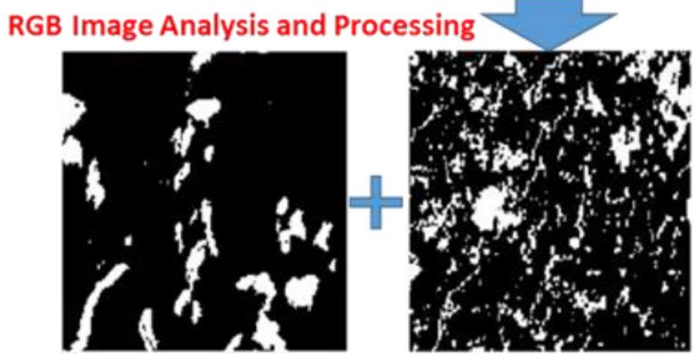

d: SBS modifier

e: Filler

Fig. 3 Explanation of SBS morphology characterization steps

and the right one shows the mineral powder and fine aggregate distribution, while the left one shows the SBS modifier.

The six parameters used to characterize the SBS morphologies in the mortar transition zone are SBS area ratio, SBS box dimension, area-weighted average axis ratio of SBS, coefficient of variation in axis ratio, SBS average particle area, and coefficient of variation in average particle area. A wider range of microscope images of $1000 * 1000$ pixels was used in the statistical evaluation to ensure the accuracy of image analysis. Furthermore, these six indicators are calculated by self-programming in MATLAB. Their representative physical meanings are explained in Table 4. The more uniform the particle distribution in the two-dimensional area is, the closer the box dimension of the region is to 2 . Figure 4 explains the relationship between box dimension and particle distribution uniformity in areas of the same size. The exact number of particles of the same size are placed in the same block but with different distribution uniformity. Obviously, the better the uniformity is, the closer the box dimension is to 2 .

The axis ratio of the SBS modifier was calculated from fluorescence image analysis to quantify the shape of SBS particles in the mixture phase. It is defined as the axis ratio of the equivalent oval-shaped area of the analyzed twodimensional SBS particle. The area-weighted average axis ratio was then defined and used to minimize the influence of particle areas. The area-weighted average axis ratio can be calculated with Eq. (1), and Eq. (3) explains the calculation of the coefficient of variation in the axis ratio.

$$
\begin{aligned}
& M=\frac{\sum_{i=1}^{n} A_{i} \times P_{i}}{\sum_{i=1}^{n} A_{i}} \\
& S=\sqrt{\frac{\sum_{i=1}^{n} A_{i} \times\left(P_{i}-M\right)^{2}}{\sum_{i=1}^{n} A_{i}}}
\end{aligned}
$$

Table 4 Physical meaning of the used microscopic morphological parameters

\begin{tabular}{ll}
\hline Microscopic morphological parameters & Physical meaning \\
\hline SBS area ratio [\%] & Volume fraction of SBS modifier in \\
SBS box dimension (D) & mortar at two-dimensional condition \\
Area-weighted average axis ratio of SBS & Distribution uniformity of SBS modifier \\
Coefficient of variation in axis ratio & SBS particle shape \\
SBS average particle area $\left[\mu \mathrm{m}^{2}\right]$ & SBS particle shape distribution \\
Coefficient of variation in SBS average particle area & SBS particle size \\
\hline
\end{tabular}




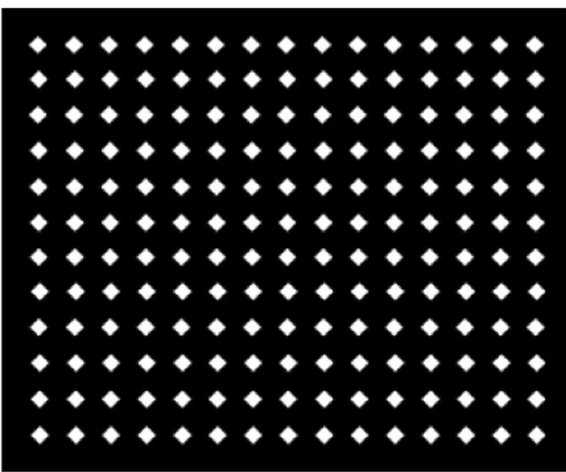

Box dimension is 1.8359

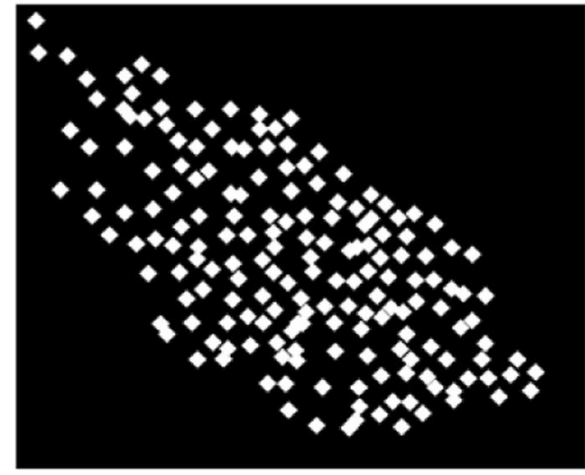

Box dimension is 1.6361
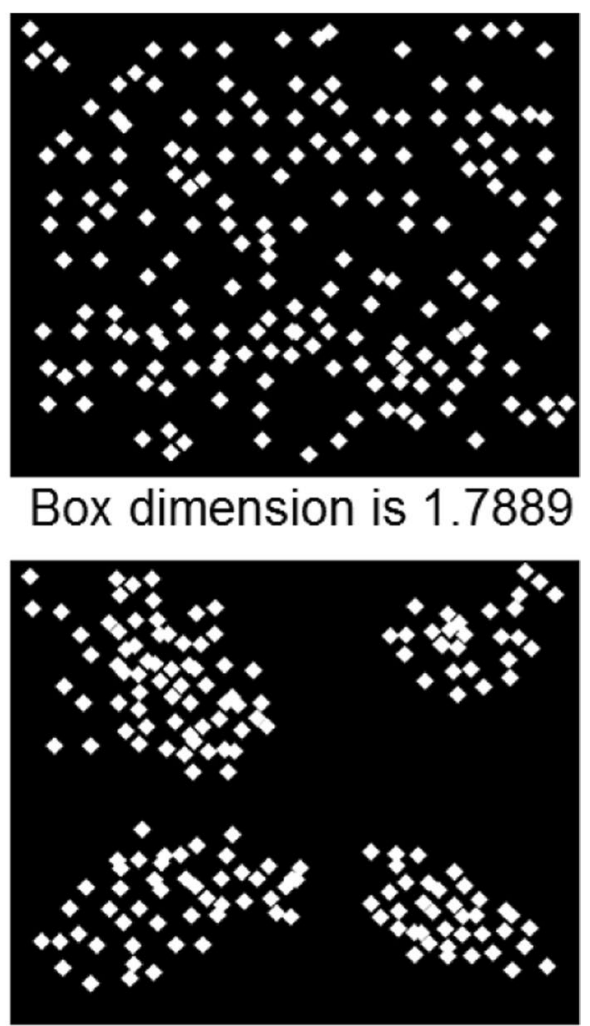

Box dimension is 1.5332

Fig. 4 Graphic explanation of the relation between box dimension and particles distribution uniformity

$$
C . V=\frac{S}{M} \times 100 \%
$$

Where $\mathrm{M}$ is the area-weighted average axis ratio, $A_{i}$ Is the area of no. i particle, $P_{i}$ is the equivalent oval-shaped area of no. i particle, $\mathrm{N}$ is the particle number in the analyzed area, $\mathrm{S}$ is the standard deviation of axis ratio, C.V is the coefficient of variation in axis ratio.

\section{Results and discussion}

\section{SBS micro-morphologies in mix}

The influence of modification conditions on SBS micromorphologies in asphalt mixtures was studied with the help of the thin section preparation method and fluorescence image analysis. Magnification of 200 times for fluorescence images was presented in Figs. 5, 8, and 11. In this research, the modification conditions have the following three categories.

- The SBS adds ratio dependency: the SBS adding ratios include $2 \mathrm{wt} \%$ (weight), $3 \mathrm{wt} \%$, $4 \mathrm{wt} \%$, $5 \mathrm{wt} \%$, and $7 \mathrm{wt} \%$, under the shearing conditions $160^{\circ} \mathrm{C}$ for temperature and $3500 \mathrm{rpm}$ for shearing rate.
- Modification temperature dependency: the modification temperatures include $130^{\circ} \mathrm{C}, 145^{\circ} \mathrm{C}, 160^{\circ} \mathrm{C}$, and $175^{\circ} \mathrm{C}$, under a shearing rate of $3500 \mathrm{rpm}$ and a $30 \%$ adding ratio.

- Temperature dependency: the modification temperatures include $130^{\circ} \mathrm{C}, 145^{\circ} \mathrm{C}, 160^{\circ} \mathrm{C}$, and $175^{\circ} \mathrm{C}$, under a shearing rate of $3500 \mathrm{rpm}$ and a $30 \%$ adding ratio.

- The Shearing rate dependency: the shearing rates include $2000 \mathrm{rpm}, 3500 \mathrm{rpm}$, and $5000 \mathrm{rpm}$, under a modification temperature of $160^{\circ} \mathrm{C}$ SBS adding ratio was $2 \mathrm{wt} \%$ and $7 \mathrm{wt} \%$.

\section{SBS adding ratio dependency}

Figure 5 shows the fluorescence microscopy images of the SBS modifier in the asphalt mixtures under blue excitation light. It illustrates that the cross-section of an asphalt mixture with a flat surface can be successfully used in fluorescence microscopy analysis. The distribution of the SBS modifier in the mortar transition zone can be detected under blue excitation light. Higher SBS content in the asphalt binder will result in a more bright green-yellow area in the fluorescence microscopy images 

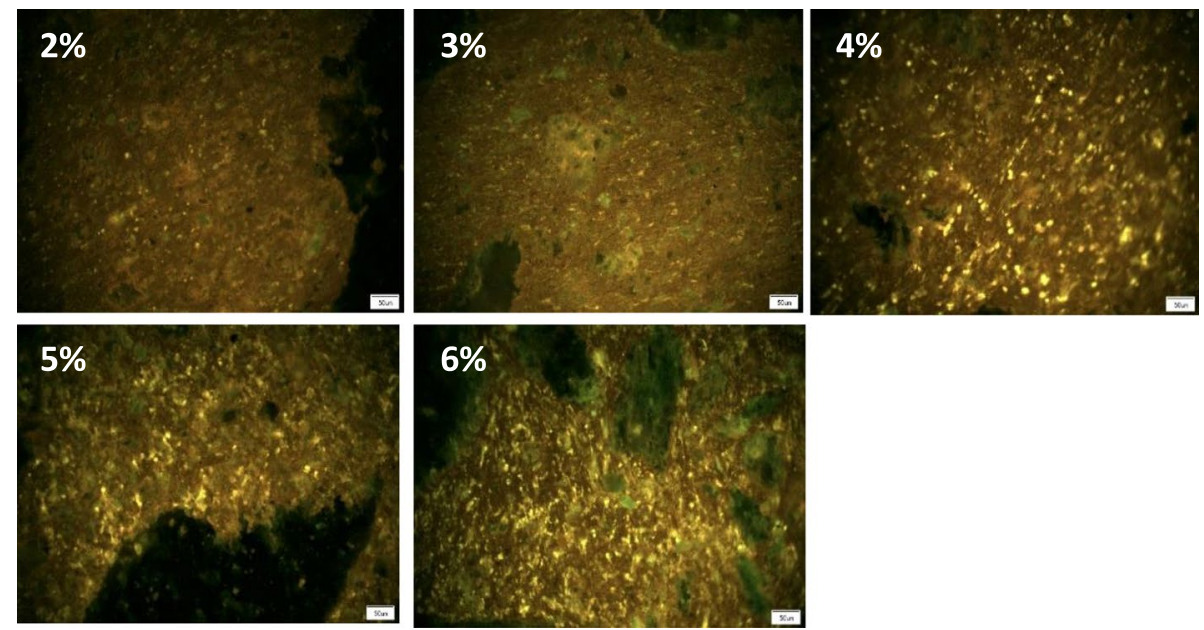

Fig. 5 Fluorescence images of SBS modifier in mixtures at a different adding ratio (image size: $1.4 \mathrm{~mm} \times 1.0 \mathrm{~mm}$ )

of the mortar transition zone, representing a higher area ratio of the SBS modifier in the asphalt mortar.

The morphology parameters were then plotted in Fig. 5 for further analysis. Figures 6 and 7 presents how the six micromorphology parameters of the SBS modifier vary with modifier content. It can be seen from Fig. 6 that with the increase in SBS content, the SBS area ratio in asphalt mortar first rises and then decreases, reaching the highest value of $7.86 \%$ at $5 \mathrm{wt} \%$ content, indicating that the asphalt mixture preparation process of different SBS content has different effects on the SBS area ratio. Figure 6 also shows that with the increase in SBS content, the box dimension increased initially. The reason is that the number of polymer particles in the $3 \mathrm{wt} \%$
SBS sample significantly increased compared with the $2 \mathrm{wt} \%$ sample, which improves the dispersion uniformity in asphalt mortar. So the detected image morphologies of SBS particles in the mortar transition zone will be changed, resulting in a different SBS area ratio. When SBS content is increased to $5 \mathrm{wt} \%$, the SBS particle size in asphalt mortar is more prominent, and the distribution is denser than in the lower content samples. However, due to the SBS dispersion in asphalt mortar becoming worse, which is related to the superfluous SBS modifier in the binder at too high a ratio, the box dimension decreases significantly.

Figure 7 illustrates that when the content increases from $3 \mathrm{wt} \%$ to $7 \mathrm{wt} \%$, the particle area first rises sharply

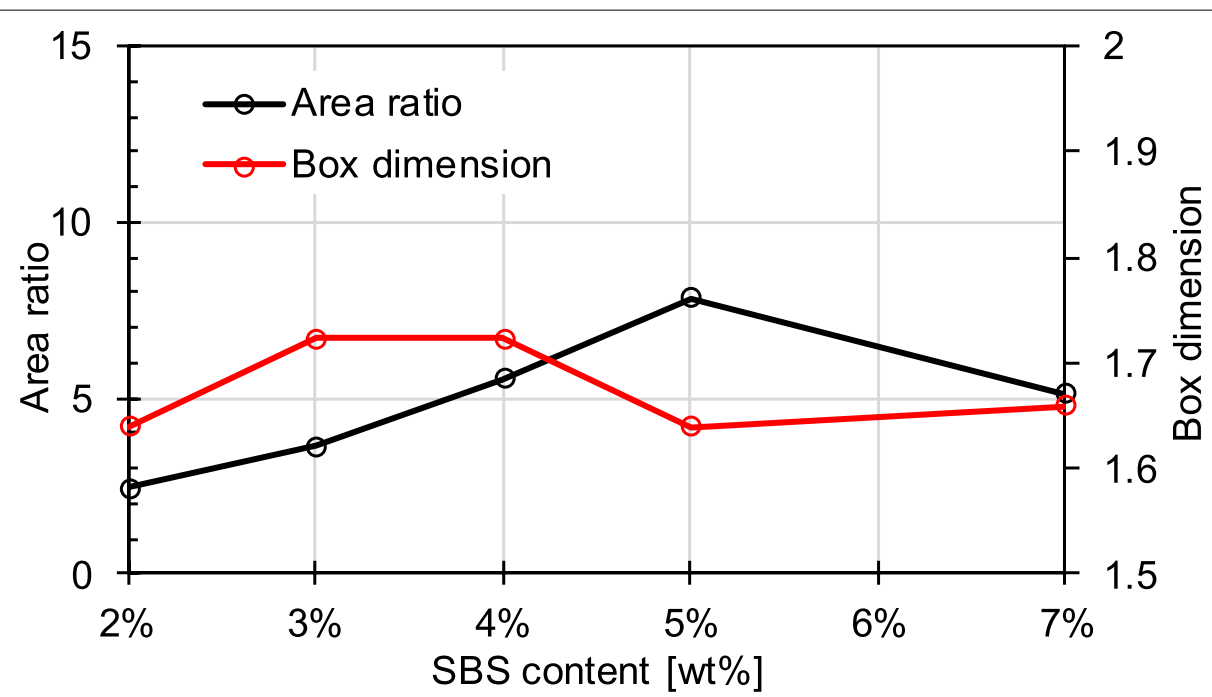

Fig. 6 Influence of SBS content on the area ratio and box dimension in mix 


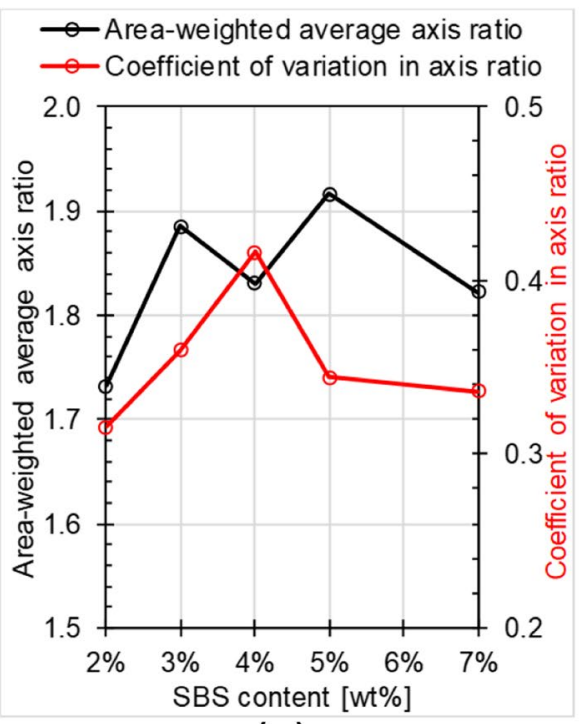

(a)

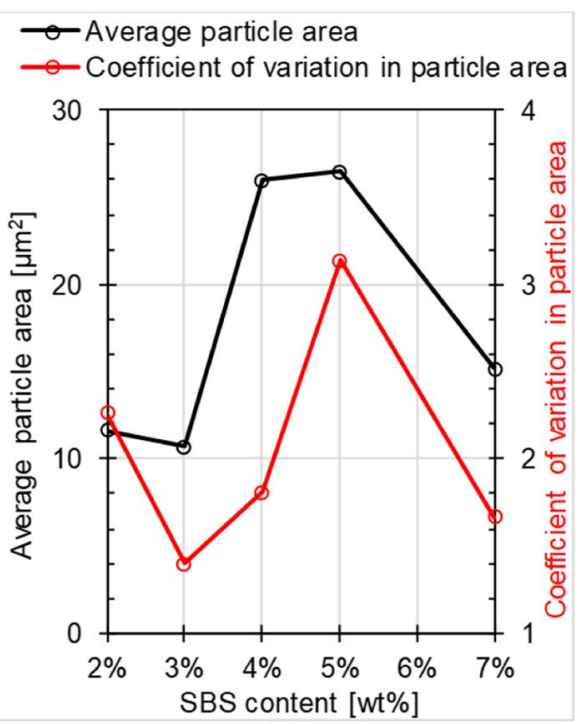

(b)

Fig. 7 Influence of SBS content on the axis ratio (a) and particle area (b) in mix

and then decreases, so it has no linear relationship with the SBS content in a binder. The trend of the area variation coefficient is similar to the particle area curve. When the adding ratio increases from $5 \mathrm{wt} \%$ to $7 \mathrm{wt} \%$, the size difference between SBS particles in asphalt mortar becomes smaller, and the dispersion is better. In addition, Fig. 7 shows that the area-weighted average axis ratio in asphalt mortar fluctuates in the range of 1.732 to 1.916 , and the coefficient of variation remains at a low level, indicating that the content has little effect on the shape of polymer particles in the asphalt mortar.

\section{Modification temperature dependency}

Figure 8 presents interesting differences in fluorescence images resulting from different modification temperatures. Specimens with binder modified at $130^{\circ} \mathrm{C}$ have the brightest color of SBS particles, while specimens with binder modified at other three higher temperatures have a darker color. The reason is that $130^{\circ} \mathrm{C}$ is not enough to ensure a homogenous distribution. The size of shining particles of $130^{\circ} \mathrm{C}$ specimens varied from 8 to $40 \mu \mathrm{m}$, illustrating that the SBS modifiers were not well dispersed $[3,7,21]$. When the modification temperature increases, the size of dispersed SBS particles decreases, and therefore, the fluorescence image gets a bit darker.

Figure 9 presents the influence of modification temperature on the particle area and axis ratio of the SBS modifier in the mortar transition zone. It agrees with Fig. 8 that the SBS particles got much smaller when their modification temperature increased from $130^{\circ} \mathrm{C}$ to $145^{\circ} \mathrm{C}$. Specimens with binder modified at $145^{\circ} \mathrm{C}, 160^{\circ} \mathrm{C}$, and $175^{\circ} \mathrm{C}$ had similar values of particle area of SBS modifier. The coefficient of variation in particle area presents the same changing law. The parameter of the average axis ratio and its coefficient of variation had the same relation to modification temperature as that of particle areas. Specimens with binder prepared at a modification temperature of $145^{\circ} \mathrm{C}$ have the lowest average axis ratio. It illustrates that a higher modification temperature is necessary to decrease the SBS particle size and axis ratio.

Figure 10 concludes the relationship between area ratio and modification temperature, as well as the relationship between box dimension and modification temperature. The box dimension of tested specimens varies from 1.63 to 1.72 , showing no apparent relationship with the modification temperature. Higher modification temperature would result in smaller SBS particles in the mortar area, resulting in a change of area ratio from 5.34 to $1.5 \%$ when the modification temperature increased from $130^{\circ} \mathrm{C}$ to $145^{\circ} \mathrm{C}$. However, higher modification temperatures of $160^{\circ} \mathrm{C}$ and $170^{\circ} \mathrm{C}$ will promote the swelling process of the SBS modifier, resulting in a slight increase in area ratio $[11,28,29]$.

\section{Shearing rate dependency}

Figure 11 shows the fluorescence microscopy images of the SBS modifier in the mixtures with binder modified by the different shearing rates. Firstly, the fluorescence images of the $2 \mathrm{wt} \%$ SBS group and the $7 \mathrm{wt} \%$ SBS group had significant differences. Specimens of the $7 \mathrm{wt} \%$ SBS group had significantly brighter fluorescence images than those of the $2 \mathrm{wt} \%$ SBS group. Secondly, the influence of 

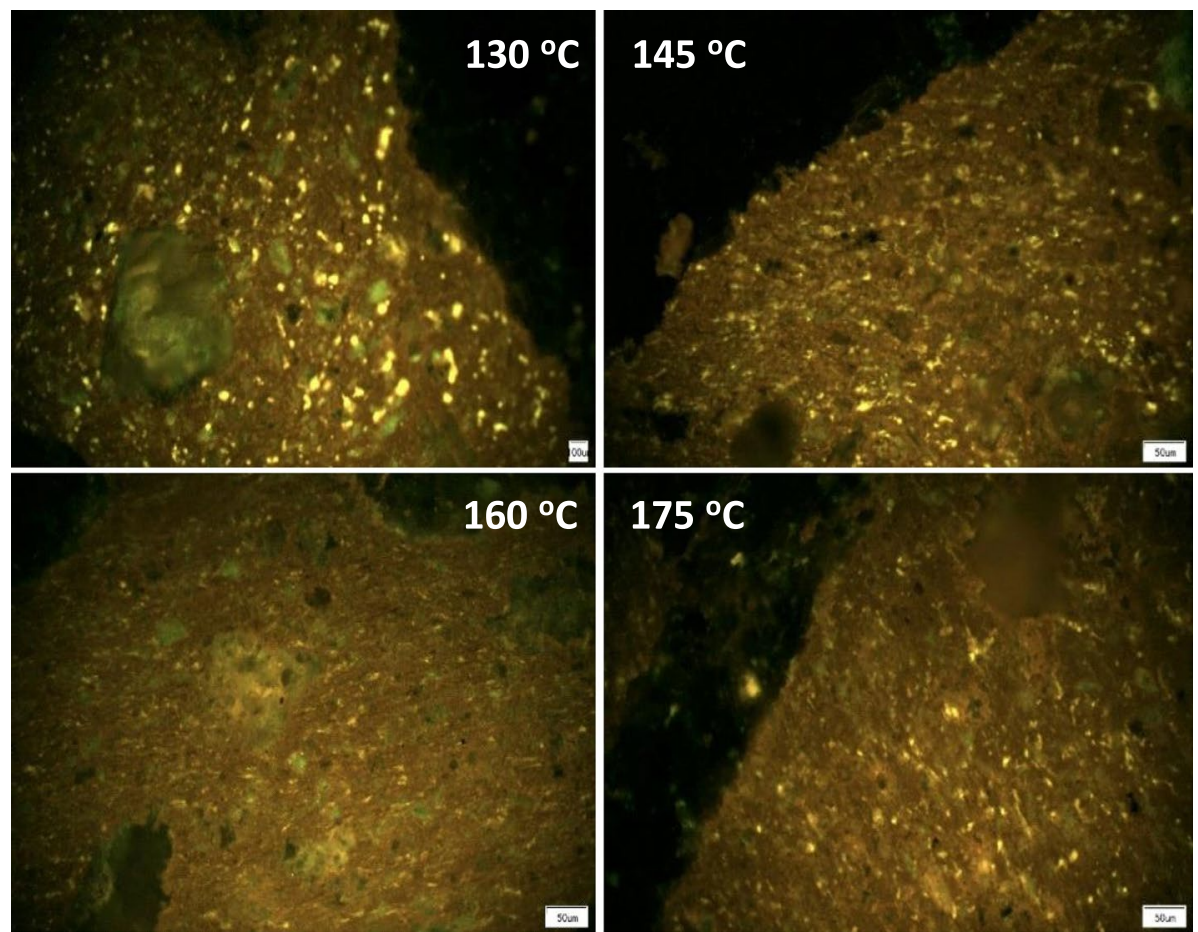

Fig. 8 Fluorescence images of SBS modifier in mixtures at different conditioning temperature (image size: $1.4 \mathrm{~mm} \times 1.0 \mathrm{~mm}$ )

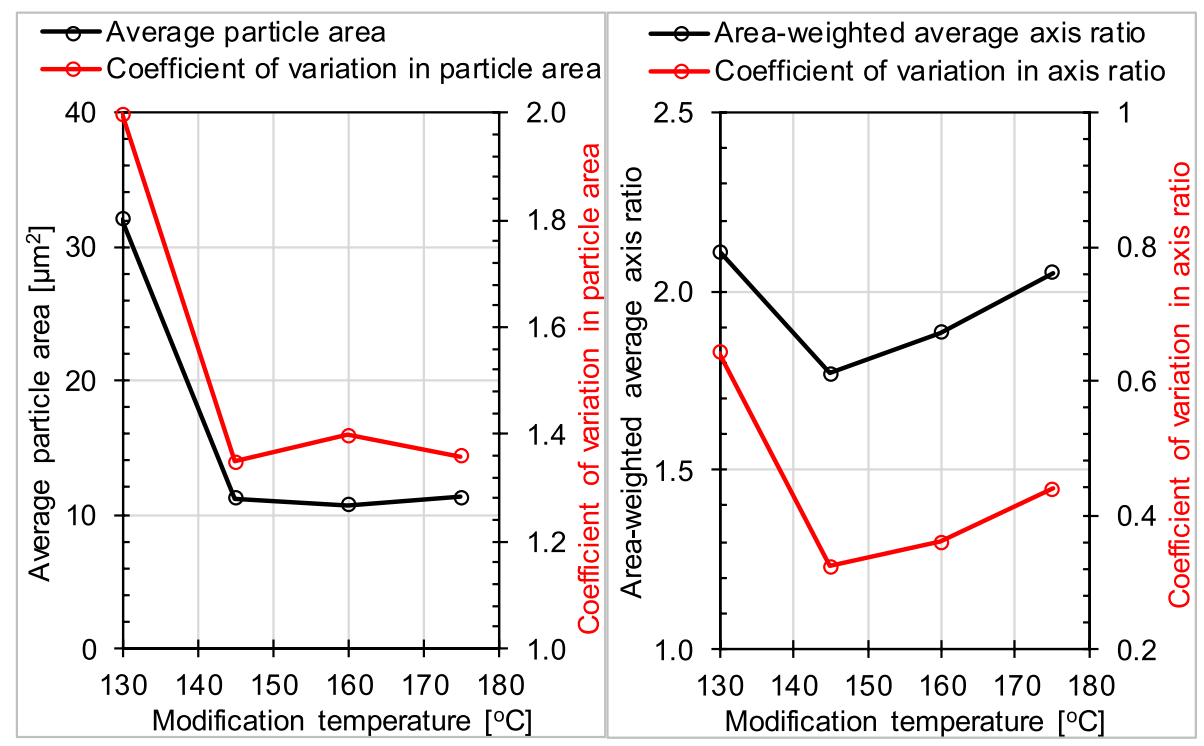

Fig. 9 Influence of modification temperature on the particle area and axis ratio in the mix

the shearing rate was highlighted in the case of the $7 \mathrm{wt} \%$ SBS group. Differences in fluorescence images due to increasing shear rate were negligible when a $2 \mathrm{wt} \%$ modified binder was used, while there were apparent differences with a $7 \mathrm{wt} \%$ modified binder.
Table 5 concludes the micro-morphologies of SBS particles in mixtures with asphalt binder modified at different shearing rates. It shows that the area ratio increases with the increase in shearing rate, both in the $2 \mathrm{wt} \%$ SBS group and the $7 \mathrm{wt} \%$ SBS group. Specimens of the $7 \mathrm{wt} \%$ 


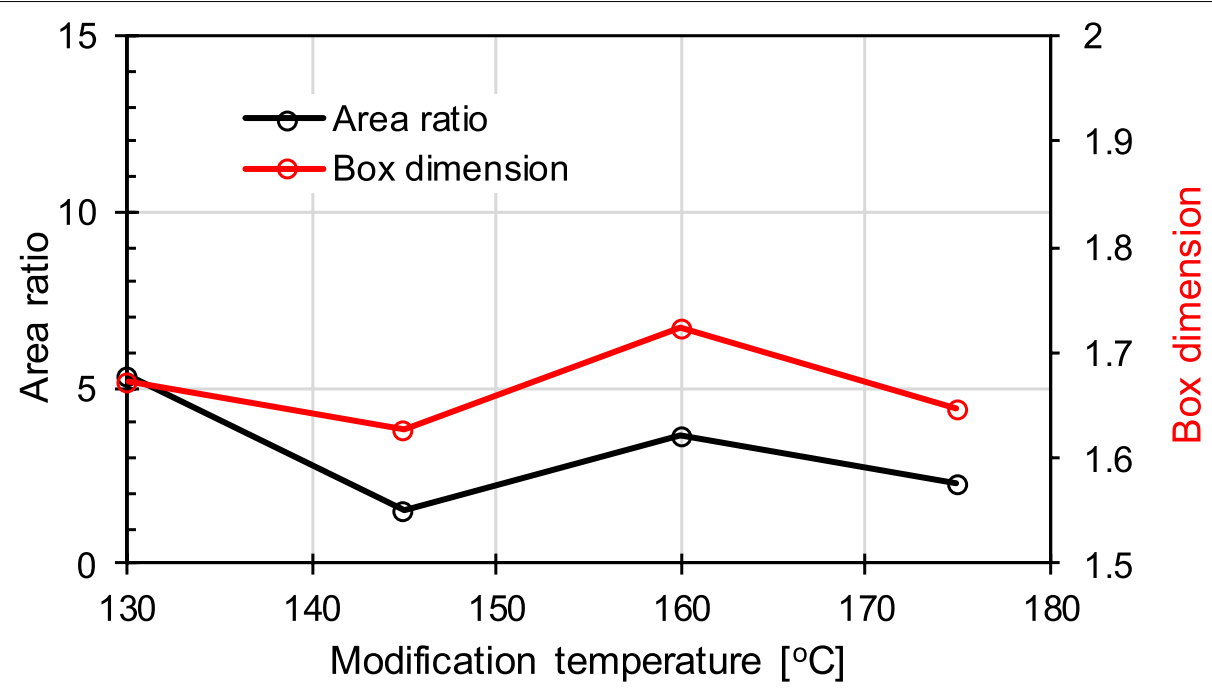

Fig. 10 Influence of modification temperature on the area ratio and box dimension in mix

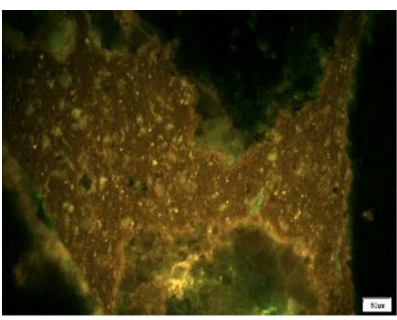

2\%@ 2000rpm

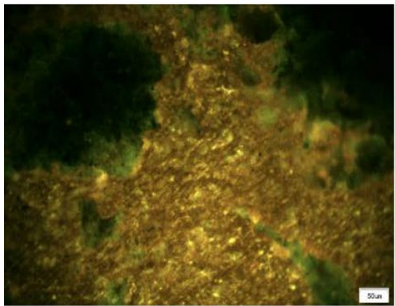

7\% @ 2000rpm

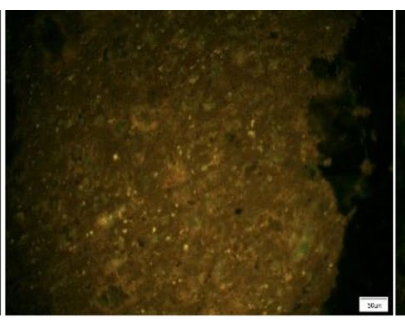

2\%@ 3500rpm

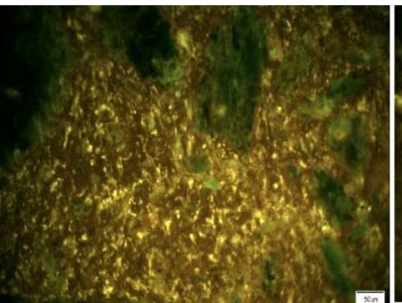

7\% @ 3500rpm

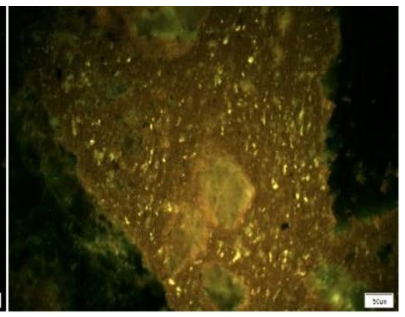

2\% @ 5000rpm

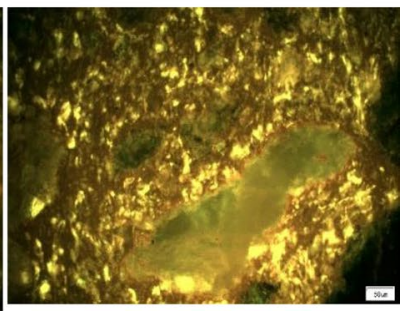

7\% @ 5000rpm

Fig. 11 Fluorescence images of SBS modifier in mixtures at a different shearing rate (image size: $1.4 \mathrm{~mm} \times 1.0 \mathrm{~mm}$ )

Table 5 Influence of shearing rate on the micro-morphologies of SBS in the mix

\begin{tabular}{|c|c|c|c|c|c|c|}
\hline \multirow{2}{*}{$\begin{array}{l}\text { SBS adding ratio [wt\%] } \\
\text { Shear rate [rpm] }\end{array}$} & \multicolumn{3}{|l|}{$2 \%$} & \multicolumn{3}{|l|}{$7 \%$} \\
\hline & 2000 & 3500 & 5000 & 2000 & 3500 & 5000 \\
\hline Area ratio [\%] & 0.373 & 2.412 & 2.47 & 3.959 & 5.126 & 5.971 \\
\hline Box dimension & 1.355 & 1.639 & 1.415 & 1.659 & 1.660 & 1.619 \\
\hline Area-weighted average axis ratio & 1.608 & 1.732 & 1.851 & 2.171 & 1.823 & 2.124 \\
\hline Coefficient of variation in area-weighted average axis ratio & 0.508 & 0.336 & 0.385 & 0.306 & 0.316 & 0.335 \\
\hline Average particle area $\left[\mu \mathrm{m}^{2}\right]$ & 6.408 & 11.648 & 6.096 & 15.452 & 15.191 & 27.685 \\
\hline Coefficient of variation in average particle area & 1.470 & 2.264 & 1.576 & 3.034 & 1.666 & 2.500 \\
\hline
\end{tabular}


SBS group almost have a linear relationship between area ratio and shearing rate, while their box dimension stays constant. Specimens of the $2 \mathrm{wt} \%$ SBS group have the highest area ratio and box dimension at the shearing rate of $3500 \mathrm{rpm}$. Specimens of the $7 \mathrm{wt} \%$ SBS group have a highest average particle area than those of the $2 \mathrm{wt} \%$ SBS group, while specimens with $5000 \mathrm{rpm}$ and $7 \mathrm{wt} \%$ SBS have the highest particle area of $27.7 \mu \mathrm{m}^{2}$. The coefficient of variation in the area-weighted average axis ratio and the coefficient of variation in average particle area show the same relationship to the shearing rate.

\section{Micro-morphologies in mixtures and their corresponding binder}

Besides the micro-morphologies of the SBS modifier at the transition zone in asphalt mixtures, SBS micromorphologies in asphalt binder were also studied by the same image processing methods described in Micromorphology characterization method section. Moreover, the micro-morphologies of SBS in the asphalt binder phase, including area ratio, box dimension, area-weighted average axis ratio, and average particle area, were compared to the characteristics of their corresponding mixtures to illustrate the changes of SBS particles from the binder phase to the mixture phase.

Figure 12 presents the differences in area ratio for the SBS modifier in the asphalt binder and their corresponding mixtures. It shows that the area ratio of the SBS modifier in asphalt mixtures is lower than that in the binder, with only one exception. Mortar in the asphalt mixture includes asphalt binder, filler, and fine aggregate. The filler occupies a specific volume in the mortar, resulting in a lower area ratio of the SBS modifier [14]. Specimens prepared at $3 \mathrm{wt} \%$ adding ratio, $130{ }^{\circ} \mathrm{C}$ modification temperature, and $3500 \mathrm{rpm}$ shear rate present a slightly opposite trend. The modification temperature of $130^{\circ} \mathrm{C}$ was not high enough to ensure sufficient swelling for SBS particles in the modified binder. At the same time, hot mixing conditions would additionally promote the swelling process, resulting in a more significant area ratio of SBS particles in the mixture than in its binder [7, 28].

Figure 13 compares the differences in average particle area for the SBS modifier in the asphalt binder and their corresponding mixtures. When the average particle area in the asphalt binder is higher than $50 \mu \mathrm{m}^{2}$, it will lower the average particle area in its mixture. When it is lower than $50 \mu \mathrm{m}^{2}$, a higher value of average particle area will be obtained in its mixture. For instance, in the cases of 4\%-160C, 5\%-160C, 7\%-160C, 7\%-2000 rpm, and $7 \%-5000 \mathrm{rpm}$, the average particle area was significantly reduced from the binder situation to the mixture situation. It illustrated that when the average particle area is big enough, the friction stress between fine aggregates and filler during the compaction process might further separate the SBS modifier, resulting in a lower value of average particle area from binder condition to mixture condition $[4,24]$.

The binder prepared at $130^{\circ} \mathrm{C}$ of modification temperature has the highest increasing average particle area from the binder phase to the mixture phase. It agrees with Fig. 11 that the hot mixing process will promote the swelling of SBS particles that have not got sufficient swelling due to the low modification temperature.

Figure 14 illustrates that all the box dimension values of SBS particles in the asphalt mixture are lower than those in the asphalt binder. According to the definition

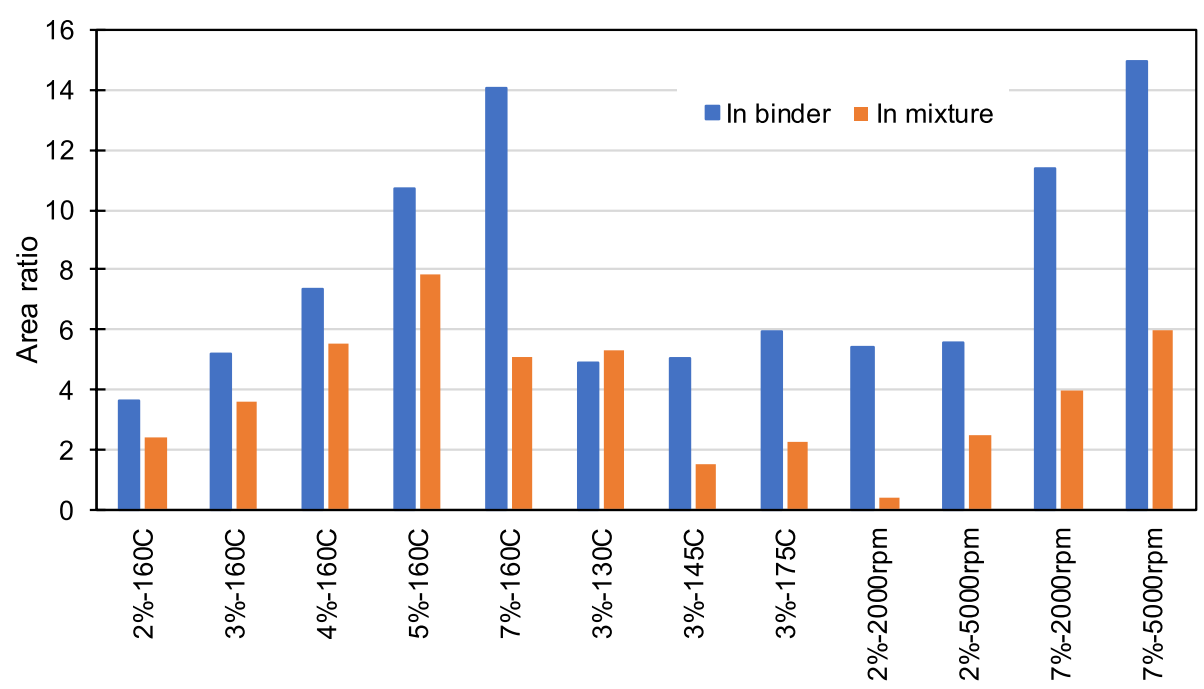

Fig. 12 Comparison of SBS area ratio in asphalt binder and their mixtures 


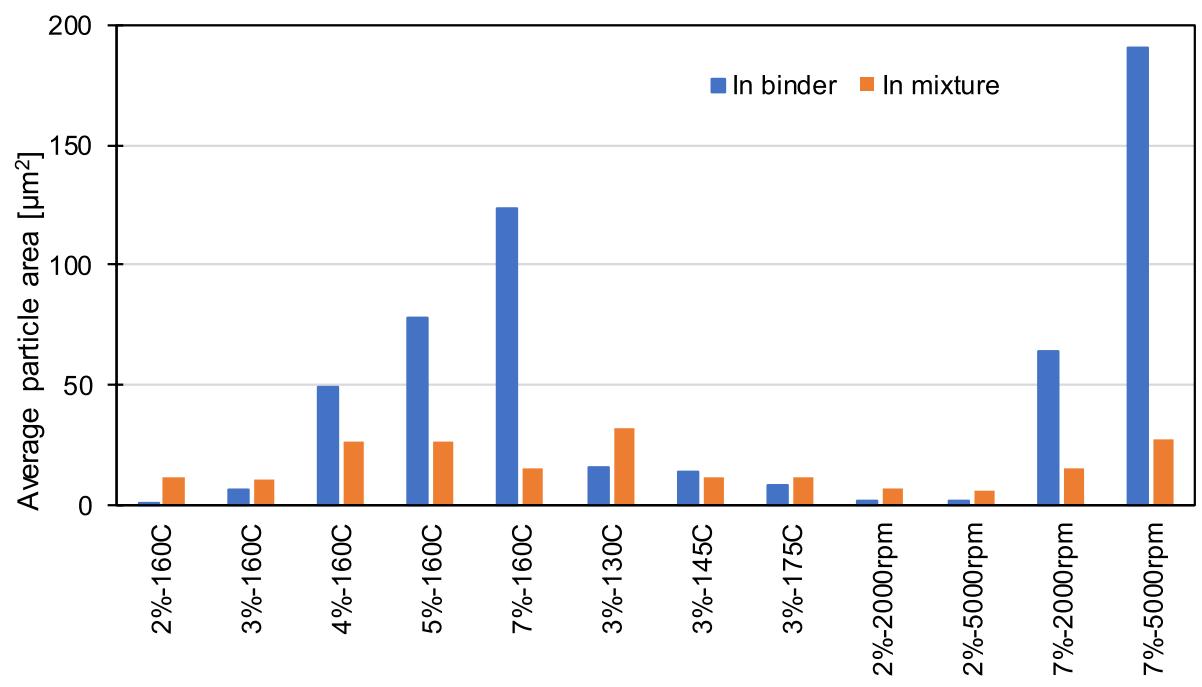

Fig. 13 Comparison of SBS average particle area in asphalt binder and their mixtures

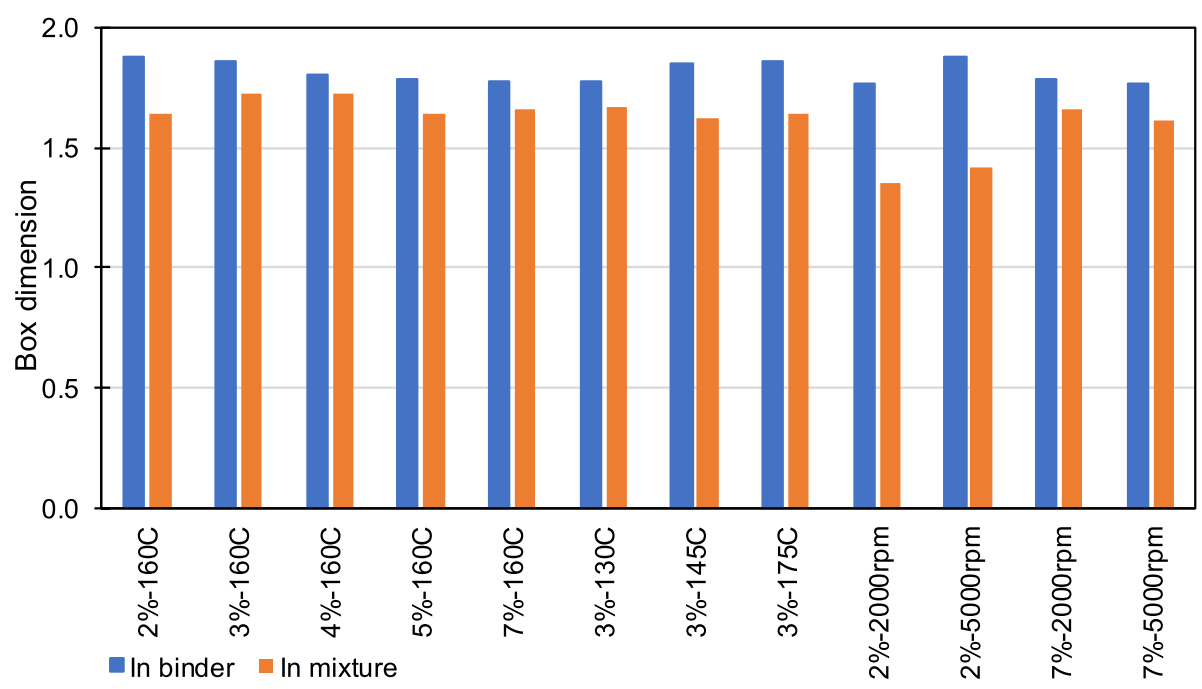

Fig. 14 Comparison of box dimension in asphalt binder and their mixtures

of box dimension, the closer to 2 box dimensions, the better the particle distribution will be. The differences described in Fig. 14 indicate that the distribution of the SBS modifier in the asphalt mixture is worse than in the asphalt binder. Fine aggregate and filler, which have particles with a similar diameter to SBS particles varying around $75 \mu \mathrm{m}$, would negatively influence the distribution of the SBS modifier. The area-weighted average axis ratio of the SBS modifier described in Fig. 15 shows slight differences from the binder phase to the mixture phase. Most of them were lower than 2, a pretty low value that means good sphericity of the SBS modifier.

\section{Conclusions}

A quantitative analysis of the SBS distribution characteristics in the asphalt mixture was introduced in this study. The influence of the SBS modification condition on the final SBS micro-morphologies was also quantified. From the discussed results, the following conclusions can be drawn:

1. The introduced cross-section preparation and fluorescence microscopy image analysis can be used to determine the SBS micro-morphology characteristics 


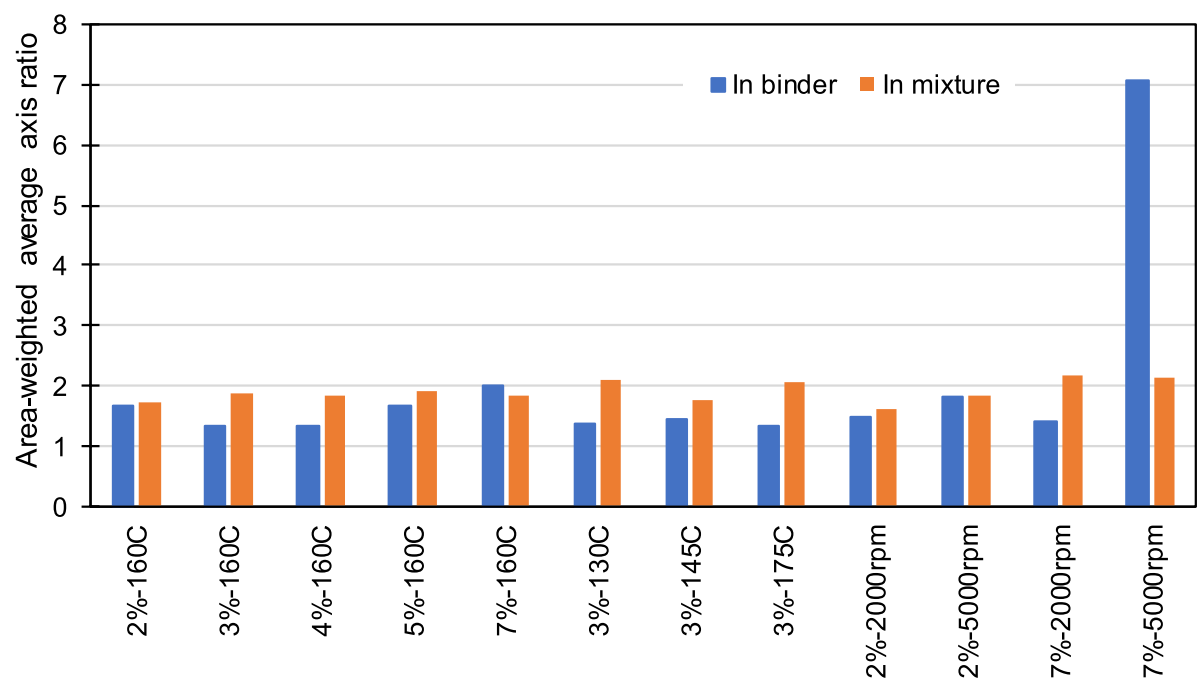

Fig. 15 Comparison of SBS area-weighted average axis ratio in asphalt binder and their mixtures

in the mortar transition zone of the asphalt mixture quantitatively. The life extension of the SBS modified asphalt mixture can be improved with a better distributed SBS modifier in the mixture.

2. SBS content significantly affects the volume fraction of SBS particles in asphalt mortar. With the increase of SBS adding content, SBS average particle area, area-weighted average axis ratio, and their coefficient of variation increase. While superfluous SBS modifiers in the binder at a higher ratio, for instance, $7 \mathrm{wt} \%$, as proved in this study, will decrease the value of the box dimension.

3. Too much lower modification temperature worsens the SBS modifier in the mixture, resulting in a wide range of particle size, higher axis ratio, and higher area ratio. The area ratio increases with the shearing rate and adding ratio, while a higher shearing rate would break the SBS network and weaken the final mechanical properties. Specimens at $3500 \mathrm{rpm}$ have the lowest coefficient of variation in area-weighted average axis ratio, indicating a better homogeneous SBS particle shape.

4. The micro-morphologies of SBS in the asphalt mixture phase varied from the asphalt binder phase. The area ratio of the SBS modifier in the mixture phase was lower than that in the binder phase, and the binder prepared at $130^{\circ} \mathrm{C}$ had the highest increasing percentage of average particle area from the binder phase to the mixture phase. The mineral filler and fine aggregate, together with an additional heating process from the mixing stage, will significantly influence the swelling state and particle size of the SBS modifier.

\section{Abbreviations}

RGB: Red Green Blue; MATLAB: Matrix Laboratory; SBS: Styrene-butadiene-styrene; D: SBS box dimension; $w t \%:$ Weight ratio.

\section{Acknowledgements}

The authors acknowledge financial support from the National Natural Science Foundation of China (No. 51878526 and 51408447). The authors would also like to thank Fok Ying Tung Education Foundation for their honorary support.

\section{Authors' contributions}

Y.X. and B.Y. designed the experiments, B.Y., X.C, and X.Z performed the experiments, $Y . X$ and $M . Y$ analyzed the data, Y.X contributed materials and analysis tools Y.X, and M.Y wrote the paper. All authors have read and agreed to the published version of the manuscript.

\section{Funding}

This work is supported by the National Natural Science Foundation of China (No. 51878526 and 51408447).

\section{Availability of data and materials}

All data generated or analyzed during this study are included in this published article.

\section{Declarations}

Ethics approval and consent to participate

Not applicable.

\section{Consent for publication}

Not applicable.

\section{Competing interests}

The authors declare no conflicts of interest.

Received: 30 May 2021 Accepted: 16 August 2021

Published online: 08 September 2021 


\section{References}

1. Abtahi SM, Sheikhzadeh M, Hejazi SM (2010) Fiber-reinforced asphaltconcrete - a review. Constr Build Mater 24(6):871-877. https://doi.org/10. 1016/j.conbuildmat.2009.11.009

2. Cuciniello G, Leandri P, Filippi S, Lo Presti D, Losa M, Airey G (2018) Effect of ageing on the morphology and creep and recovery of polymermodified bitumens. Mater Struct 51(5):136. https://doi.org/10.1617/ s11527-018-1263-3

3. Cui P, Wu S, Li F, Xiao Y, Zhang H (2014) Investigation on using SBS and active carbon filler to reduce the VOC emission from bituminous materials. Materials 7(9):6130-6143

4. Cui P, Xiao Y, Yan B, Li M, Wu S (2018) Morphological characteristics of aggregates and their influence on the performance of asphalt mixture. Constr Build Mater 186:303-312. https://doi.org/10.1016/j.conbuildmat. 2018.07.124

5. Ding Y, Huang B, Shu X (2017) Utilizing fluorescence microscopy for quantifying mobilization rate of aged asphalt binder. J Mater Civ Eng 29(12):04017243. https://doi.org/10.1061/(ASCE)MT.1943-5533.0002088

6. Ding Y, Huang B, Shu X (2018) Blending efficiency evaluation of plant asphalt mixtures using fluorescence microscopy. Constr Build Mater 161:461-467. https://doi.org/10.1016/j.conbuildmat.2017.11.138

7. Dong F, Zhao W, Zhang Y, Wei J, Fan W, Yu Y, Wang Z (2014) Influence of SBS and asphalt on SBS dispersion and the performance of modified asphalt. Constr Build Mater 62:1-7. https://doi.org/10.1016/j.conbuildmat. 2014.03.018

8. Eilers H (1949) The colloidal structure of asphalt. J Phys Colloid Chem 53(8):1195-1211. https://doi.org/10.1021/j150473a006

9. Fischer HR, Cernescu A (2015) Relation of chemical composition to asphalt microstructure - details and properties of micro-structures in bitumen as seen by thermal and friction force microscopy and by scanning near-filed optical microscopy. Fuel 153:628-633. https://doi.org/10. 1016/j.fuel.2015.03.043

10. Hassan NA, Khan R, Raaberg J, Lo Presti D (2015) Effect of mixing time on reclaimed asphalt mixtures: an investigation by means of imaging techniques. Constr Build Mater 99:54-61. https://doi.org/10.1016/j.conbu ildmat 2015.09.009

11. He R, Liang Y, Gao L, Chen H, Yang B, Guo F, Geng J (2020) Preparation and performance assessment of asphalt emulsion modified by the fabricated SBS latex. Adv Civ Eng 2020:6699416. https://doi.org/10.1155/2020/66994 16

12. Kou C, Xiao P, Kang A, Mikhailenko P, Baaj H, Wu Z (2019) Protocol for the morphology analysis of SBS polymer modified bitumen images obtained by using fluorescent microscopy. Int J Pavement Eng 20(5):585-591. https://doi.org/10.1080/10298436.2017.1316647

13. Lesueur $D$ (2009) The colloidal structure of bitumen: consequences on the rheology and on the mechanisms of bitumen modification. Adv Coll Interface Sci 145(1):42-82. https://doi.org/10.1016/j.cis.2008.08.011

14. Lin J, Huo L, Xiao Y, Xu F, Pan P (2020) Long-term performance characteristics and interface microstructure of field cold recycled asphalt mixtures. Constr Build Mater 259:120406. https://doi.org/10.1016/j.conbuildmat. 2020.120406

15. Luo R, Zhang K, Xu W, Feng G (2017) Quantification of the tyre-track resistance of coloured asphalt mixtures. Road Mater Pavement Des 18(4):817-832. https://doi.org/10.1080/14680629.2016.1194881

16. Mangiafico S, Di Benedetto H, Sauzéat C, Olard F, Pouget S, Planque L (2016) Effect of colloidal structure of bituminous binder blends on linear viscoelastic behaviour of mixtures containing Reclaimed Asphalt Pavement. Mater Des 111:126-139. https://doi.org/10.1016/j.matdes.2016.07. 124
17. Moaveni M, Cetin S, Brand AS, Dahal S, Roesler JR, Tutumluer E (2016) Machine vision based characterization of particle shape and asphalt coating in Reclaimed Asphalt Pavement. Transp Geotech 6:26-37. https://doi. org/10.1016/j.trgeo.2016.01.001

18. Navaro J, Bruneau D, Drouadaine I, Colin J, Dony A, Cournet J (2012) Observation and evaluation of the degree of blending of reclaimed asphalt concretes using microscopy image analysis. Constr Build Mater 37:135-143. https://doi.org/10.1016/j.conbuildmat.2012.07.048

19. Pfeiffer JP, Saal RNJ (1940) Asphaltic bitumen as colloid system. J Phys Chem 44(2):139-149. https://doi.org/10.1021/j150398a001

20. Polacco G, Kř́ž P, Filippi S, Stastna J, Biondi D, Zanzotto L (2008) Rheological properties of asphalt/SBS/clay blends. Eur Polymer J 44(11):35123521. https://doi.org/10.1016/j.eurpolymj.2008.08.032

21. Ren S, Liu X, Fan W, Wang H, Erkens S (2019) Rheological properties, compatibility, and storage stability of SBS latex-modified asphalt. Materials 12(22):3683

22. Shan L, Xie R, Wagner NJ, He H, Liu Y (2019) Microstructure of neat and SBS modified asphalt binder by small-angle neutron scattering. Fuel 253:1589-1596. https://doi.org/10.1016/j.fuel.2019.05.087

23. Wan J, Wu S, Xiao Y, Fang M, Song W, Pan P, Zhang D (2019) Enhanced ice and snow melting efficiency of steel slag based ultra-thin friction courses with steel fiber. J Clean Prod 236:117613. https://doi.org/10.1016/j.jclepro. 2019.117613

24. Wang F, Xiao Y, Cui P, Ma T, Kuang D (2020) Effect of aggregate morphologies and compaction methods on the skeleton structures in asphalt mixtures. Constr Build Mater 263:120220. https://doi.org/10.1016/j.conbu ildmat.2020.120220

25. Xiao Y, Chang X, Yan B, Zhang X, Yunusa M, Yu R, Chen Z (2021) SBS morphology characteristics in asphalt binder and their relation with viscoelastic properties. Constr Build Mater 301:124292. https://doi.org/10. 1016/j.conbuildmat.2021.124292

26. Xiao Y, van de Ven MFC, Molenaar AAA, Wu SP (2013) Possibility of using epoxy modified bitumen to replace tar-containing binder for pavement antiskid surfaces. Constr Build Mater 48:59-66. https://doi.org/10.1016/j. conbuildmat.2013.06.080

27. Xiao Y, Wang F, Cui P, Lei L, Lin J, Yi M (2018) Evaluation of fine aggregate morphology by image method and its effect on skid-resistance of microsurfacing. Materials 11(6):920

28. Xu S, Yu J, Hu C, Qin D, Xue L (2017) Laboratory evaluation of rejuvenation effect of reactive rejuvenator on aged SBS modified bitumen. Mater Struct 50(6):233. https://doi.org/10.1617/s11527-017-1106-7

29. Zhang C, Wang H, You Z, Gao J, Irfan M (2019) Performance test on Styrene-Butadiene-Styrene (SBS) modified asphalt based on the different evaluation methods. Appl Sci 9(3):467

30. Zhu C, Zhang H, Zhang D, Chen Z (2018) Influence of base asphalt and SBS modifier on the weathering aging behaviors of SBS modified asphalt. J Mater Civ Eng 30(3):04017306. https://doi.org/10.1061/(ASCE)MT.19435533.0002188

31. Zhu J, Birgisson B, Kringos N (2014) Polymer modification of bitumen: advances and challenges. Eur Polymer J 54:18-38. https://doi.org/10. 1016/j.eurpolymj.2014.02.005

\section{Publisher's Note}

Springer Nature remains neutral with regard to jurisdictional claims in published maps and institutional affiliations. 